\title{
PENGARUH PENERAPAN METODE 5S (SEIRI, SEITON, SEISO, SEIKETSU, DAN SHITSUKE) TERHADAP PEMELIHARAAN ALAT KESEHATAN DI RUMAH SAKIT UMUM IMELDA PEKERJA INDONESIA MEDAN
}

\author{
${ }^{1}$ Paskah Rina Situmorang, ${ }^{2}$ Hamonangan Damanik \\ 1,2. Dosen Prodi S-1Keperawatan, STIKes Imelda, Jalan Bilal Nomor 52 Medan \\ E-mail: ${ }^{1}$ paskahsitumorang85@gmail.com \\ 2hamonangan1112@gmail.com
}

\begin{abstract}
ABSTRAK
Peralatan kesehatan merupakan salah satu faktor yang berperan penting dalam menyelenggarakan pelayanan kesehatan kepada masyarakat. Pelayanan kesehatan yang diberikan kepada pasien harus dilaksanakan secara berkesinambungan dan didukung dengan adanya peralatan yang selalu dalam kondisi siap pakai serta dapat berfungsi dengan baik. Upaya yang dilakukan oleh tenaga kesehatan di rumah sakit adalah dengan upaya penyediaan alat kesehatan yang baik, aman dan siap pakai. Agar peralatan kesehatan dalam keadaan siap pakai perlu diadakan pemeliharaan yang pereventif melalui pemeliharaan alat-alat dengan baik. Penelitian ini bertujuan untuk mengidentifikasi pengaruh penerapan metode 5 S terhadap pemeliharaan alat kesehatan di Rumah Sakit Umum Imelda Pekerja Indonesia. Jenis penelitian ini adalah kuantitatif dengan metode quasi experimental study dengan desain one group pre test-post test. Populasi dalam penelitian ini/adalah seluruh perawat yang ada di rumah sakit umum Imelda pekerja Indonesia medanberjumlah 126 orang perawat. Teknik pengambilan sampel adalah Acidental Sampling. Hasil penelitian didapatkan dari data demografi perawat yang bekerja di RSU IPI berdasarkan unsia mayoritas berusia 21-30 tahun sebanyak 91 orang dan minoritas berusia 41-50 tahun sebanyak 3 orang, berdasarkan jenis kelamin mayoritas berjenis kelamin perempuan sebanyak 87 orang dan minoritas berjenis kelamin laki-laki sebanyak 39 orang, berdasarkan tingkat pendidikan perawat mayoritas berpendidikan D3 keperawatan sebanyak 108 orang dan mayoritas berpendidikan D4 keperawatan sebanyak 1 orang, dan berdasarkan lama bekerja mayoritas masa kerja perawat 1-5 tahun sebanyak 82 orang dan minoritas dengan masa kerja 11-15 tahun sebanyak 20 orang. Dan hasil uji statistik diperoleh bahwa ada pengaruh penerapan metode 5 S terhadap pemeliharaan alat kesehatan dengan menggunakan uji statistik Mc Nemar sebesar 0,002. Setelah intervensi penerapan metode $5 S$ terhadap pemeliharaan alat kesehatan mengalami peningkatan yaitu dalam kategori baik. Saran kepada seluruh perawat agar terus melakukan proses pemeliharaan alat kesehatan dengan baik sehingga alat-alat di ruangan dalam keadaan bersih, rapi, dan keadaan siap pakai sehingga dapat meningkatkan mutu pelayanan asuhan keperawatan kepada pasien dan juga dapat mengurangi angka kematian.
\end{abstract}

Kata Kunci : 5 s, Pemeliharaan Alat Kesehatan, Perawat.

\section{PENDAHULUAN}

Rumah sakit merupakan suatu unit pelayanan kesehatan yang menyelenggarakan pelayanan kesehatan kepada masyarakat dengan menyediakan pelayanan kesehatan dirumah sakit baik rawat jalan maupun rawat inap. Perawat merupakan sumber daya terbesar (40-60\%) dari tenaga kesehatan di rumah sakit yang menjadi pelaksana dalam pelayanan kesehatan terhusus dalam hal asuhan keperawatan yang ikut berkontribusi terhadap rendahnya kualitas pelayanan sehingga akan menimbulkan dampak buruk terhadap pelayanan. Berdasarkan fakta yang diperoleh di lapangan menyebutkan $80 \%$ responden mengeluh ketidak puasan terhadap layanan keperawatan yang diberikan kepada pasien yaitu pelaksanaan asuhan keperawatan yang belum optimal, perawat cenderung lambat dan kurang tanggap dalam menjalankan tugasnya. Salah satu komponen penting dalam mendukung upaya proses penyembuhan pasien adalah peralatan kesehatan. Sebagaimana dijelaskan dalam Undang-undang Republik Indonesia Nomor 44 Tahun 2009 bahwa setiap rumah sakit akan menjamin ketersediaan alat-alat kesehatan, maka ketersediaan peralatan oleh rumah sakit sangat mempengaruhi mutu pelayanan kesehatan yang diberikan dalam 
meningkatkan kepuasan pasien. Oleh karena itu, peralatan di rumah sakit haruslah lengkap serta kondisi maupun fungsinya harus dalam keadaan baik sehingga dapat mendukung dalam pelayanan kesehatan.

World Health Organization (WHO) menyatakan lebih dari 50\% alat -alat kesehatan di Negara berkembang tidak dapat berfungsi dan tidak dapat digunakan secara optimal disebabkan kurangnya upaya dalam pemeliharaan alat kesehatan. Pemeliharaan merupakan usaha atau proses kegiatan dalam mempertahankan kondisi teknis, daya guna dan kualitas alat. Peralatan kesehatan merupakan salah satu faktor yang sangat memengang peranan penting dalam menyelenggarakan pelayanan kesehatan kepada masyarakat.

Pembinaan dan pengelolaan peralatan serta perlengkapan tidak mudah, bahkan sebaliknya akan semakin kompleks. Oleh karena itu, hal ini menuntut perhatian dan penertiban yang sangat serius. Hal ini disebabkan oleh kecenderungan timbulnya gejala yang merugikan seperti penggunaan barang yang kurang efisien dan kurang tepat, sering menimbulkan pemborosan, kurangnya kesadaran akan arti dan nilai suatu barang khususnya peralatan, administrasi yang tidak tepat baik dalam kegiatan pengadaan barang, penyimpanan, penghapusan dan pengawasan. Oleh sebab itu peranan pengelolaan peralatan dan perlengkapan di rumah sakit harus semakin diperhatikan . Oleh karena itu, rumah sakit memerlukan metode 5S untuk dapat menghilangkan ketidak efisienan, mencegah kesalahan dan membuat sesuatu pekerjaan menjadi semakin lebih lancar.

Metode 5S ini tidak sulit dipahami. Tetapi sulit untuk dapat di laksanakan dengan baik dan benar dimana memerlukan kegigihan, kebulatan tekat, usaha secara terus menerus dari staf Sikap kerja 5S akan memberikan hasil dengan praktek kerja yang lebih mudah dengan berkurangnya pemborosan waktu saat mencari dan mengambil alat- alat.

Berdasarkan observasi yang dilakukan peneliti di Rumah sakit Imelda Medan diperoleh gambaran penataan dan penyimpanan alat-alat dan peralatan tidak baik sehingga hal tersebut memberikan dampak yang sangat berpengaruh dalam proses kegiatan perawat, alat-alat disimpan dan digabung dalam satu tempat tanpa ada keterangan mengenai alat, Kurang memperhatikan kebersihan dari alat ketika selesai digunakan pada pasien dan terkadang alat disimpan tanpa membersihkannya terlebih dahulu. Oleh karena itu, peneliti ingin meneliti tentang ''Pengaruh Penerapan Metode 5S Terhadap Pemeliharaan Alat Kesehatan di Rumah Sakit Umum Imelda Pekerja Indonesia Medan Tahun 2019”.

\section{Kerangka Konsep Penelitian}

Kerangka konsep penelitian ini merupakan bagian dari tinjauan teori penelitian diatas yang akan menjadi pedoman dalam proses pelaksanaan penelitian. Dalam kerangka konsep penelitian ini akan diuraikan mengenai variable dependen dan variable independen. 


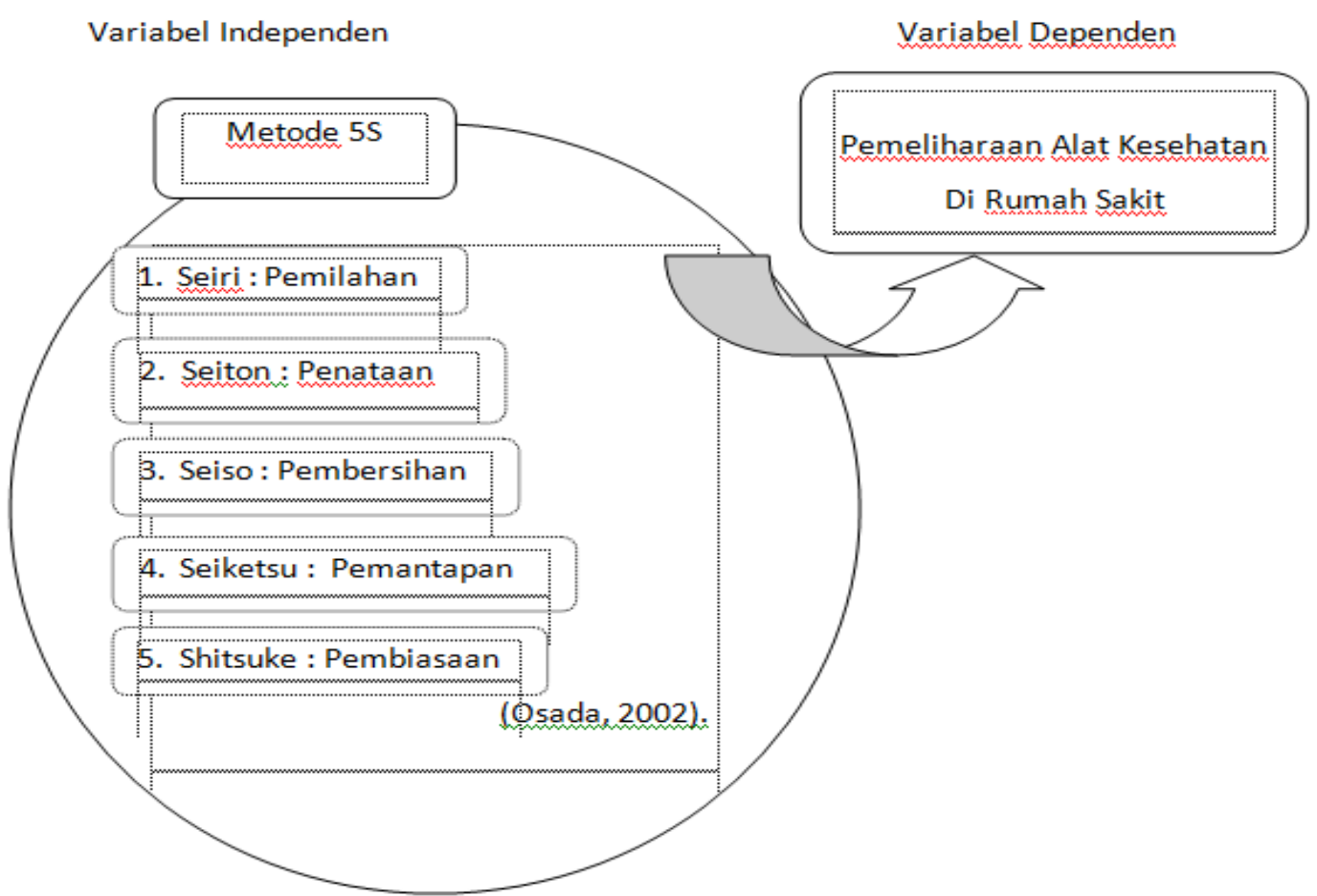

Gambar 1. Kerangka Konsep Penelitian

\section{METODE}

Penelitian ini merupakan penelitian kuantitatif dengan menggunakan rancangan penelitian metode Quasi-Experimental Study dengan desain penelitian one group pre- test-post test design yaitu suatu rancangan yang dilakukan pada satu kelompok subyek yang diberikan perlakuan (intervensi) untuk melihat efek sebelum dan sesudah perlakuan.

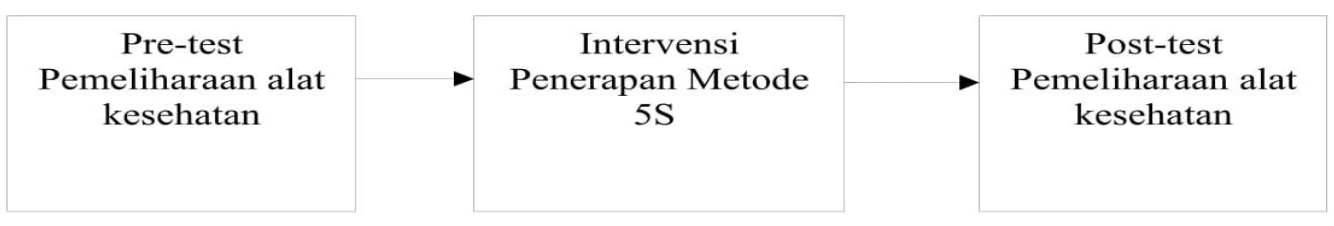

Penelitian ini bertujuan untuk mengetahui pengaruh penerapan metode $5 \mathrm{~S}$ terhadap pemeliharaan alat kesehatan sebelum dan sesudah pemberian metode $5 \mathrm{~S}$ di Rumah Sakit Imelda Pekerja Indonesia Medan, pengambilan data dilakukan mulai bulan Januari 2019, yaitu dengan melakukan penelusuran kepustakaan dan penyusunan proposal, penelitian dan analisis data. Populasi dalam penelitian ini adalah seluruh perawat yang ada di Rumah Sakit Imelda Pekerja Indonesia Medan yang berjumlah 126 orang. Teknik pengambilan sampel dalam penelitian ini adalah Acidental Sampling.

Penelitian ini dilakukan setelah mendapat persetujuan dari Kemenristek Dikti, selanjutnya peneliti mengirim surat permohonan penelitian untuk mendapatkan izin melakukan penelitian di Rumah Sakit Umum Imelda Pekerja Indonesia. Proses mengurus administrasi ini berlangsung di bulan Februari dan proses penelitian dilakukan sampai bulan Juli 2019.

\section{Prosedur sebelum penerapan metode 5S oleh perawat}

a. Pada awalnya peneliti mengusulkan kepada Kepala Bidang Keperawatan untuk membantu mengumpulkan seluruh perawat yang ada di ruangan

b. Peneliti meminta persetujuan dari calon responden untuk menandatangani informed consent setelah menjelaskan tentang tujuan, manfaat, dan prosedur penelitian. 
c. Setelah persetujuan didapat, pengumpulan data dimulai. Pertama, mengisi kuesioner data demografi yang dilakukan oleh responden. Kemudian peneliti memberikan kuesioner pemeliharaan alat kesehatan kepada perawat (pretest). Lama melakukan pretest pada masing-masing responden berkisar 10-15 menit.

\section{Prosedur saat pelaksanaan penerapan metode 5S oleh perawat}

Pelaksanaan penerapan metode 5S dilakukan setelah pretest selesai. Peneliti dengan Ka. Bid Keperawatan mengumpulkan seluruh perawat dalam satu ruangan untuk memberi penjelasan mengenai metode 5S. Selanjutnya peneliti melaksanakan penerapan metode 5S. Selain bimbingan dari peneliti, peneliti juga memberikan buku panduan penerapan metode 5S, apabila ada prosedur yang terlupa, responden bisa melihat panduan tersebut.

\section{Prosedur setelah penerapan metode $5 \mathrm{~S}$ oleh perawat}

Setelah seluruh rangkaian dari penerapan metode $5 \mathrm{~S}$ dijalankan peneliti melakukan pengukuran penerapan metode 5S berdasarkan parameter pemeliharaan alat kesehatan setelah intervensi (posttest) setelah penerapan metode $5 \mathrm{~S}$ selesai Lama dilakukan posttest berkisar 10-15 menit.

\section{Analisa Data}

Statistik univariat untuk menyajikan distribusi frekuensi data-data demografi perawat meliputi umur, jenis kelamin, pendidikan, lama kerja, distribusi frekuensi pada pemeliharaan alat kesehatan pada saat pre dan postest. Statistik bivariat menggunakan uji statistic Mc Nemar untuk melihat pengaruh penerapan metode 5S terhadap pemeliharaan alat kesehatan. Hasil analisa diperoleh jika nilai p-value $<0,05$ maka Ho ditolak, ini berarti ada pengaruh penerapan metode $5 \mathrm{~S}$ terhadap pemeliharaan alat kesehatan.

\section{HASIL}

Dari hasil Analisa Univariat diperoleh data demografi perawat yang bekerja di Rumah Sakit Umum Imelda Pekerja Indonesia Medan diperoleh bahwa usia perawat mayoritas berumur 21 - 30 tahun sebanyak 91 orang $(72,2 \%)$ dan minoritas berumur 41 - 50 tahun sebanyak 3 orang $(2,4 \%)$, berdasarkan jenis kelamin perawat yang bekerja mayoritas berjenis kelamin perempuan sebanyak 87 orang $(87 \%)$, dan minoritas berjenis kelamin laki-laki sebanyak 39 orang $(69,1 \%)$. Berdasarkan tingkat pendidikan mayoritas perawat berpendidikan D3 Keperawatan sebanyak 108 orang $(85,7 \%)$, dan minoritas berpendidikan D4 Keperawatan sebanyak 1 orang (13,5\%), Perawat yang memiliki masa kerja di Rumah Sakit Imelda Pekerja Indonesia Medan mayoritas memiliki masa kerja 1-5 tahun sebanyak 82 orang $(65,1 \%)$, dan minoritas perawat dengan masa kerja selama $11-15$ tahun sebanyak 20 orang $(15,8 \%)$.

Analisis Bivariat diperoleh dari kuesioner pemeliharaan alat kesehatan sesudah intervensi penerapan metode $5 \mathrm{~S}$ didapat bahwa nilai p-value $<0,05$ yaitu 0,002 . Hal ini menunjukkan bahwa terdapat perbedaan rerata skor yang bermakna antara nilai pretest dan posttest pada pemeliharaan alat kesehatan oleh perawat di ruangan dimana terdapat peningkatan pemeliharaan alat kesehatan oleh perawat di ruangan setelah intervensi penerapan metode $5 \mathrm{~S}$ pada (posttest) dengan menggunakan pengukuran terhadap pemeliharaan alat kesehatan lebih tinggi dibanding sebelum penerapan metode $5 \mathrm{~S}$ (pretest). Artinya hipotesa (Ho) diterima yaitu ada pengaruh penerapan metode $5 \mathrm{~S}$ terhadap pemeliharaan alat kesehatan di rauangan di rumah sakit Imelda pekerja Indonesia medan.

\section{KESIMPULAN}

Hasil penelitian menunjukkan bahwa ada perbedaan hasil pemeliharaan alat kesehatanoleh perawat diruangan sebelum dan sesudah intervensi penerapan metode 5S. Sebelum penerapan metode $5 \mathrm{~S}$ masih ada perawat ruangan yang belum melakukan proses pemeliharaan alat kesehatan dengan baik dikarenakan belum adanya pedoman yang baku dari rumah sakit mengenai pemeliharaan alat kesehatan. Setelah intervensi penerapan metode $5 \mathrm{~S}$ perawat diruangan telah memiliki pedoman mengenai pemeliharaan alat kesehatan dimana sebelum penerapan metode $5 \mathrm{~S}$ masih ada perawat diruangan 
yang belum melakukan proses pemeliharaan alat kesehatan dengan baik tetapi setelah penerapan metode $5 \mathrm{~S}$ proses pemeliharaan alat kesehatan dilakukan dengan baik.

\section{SARAN}

1. Bagi Rumah Sakit

Perlu adanya pelatihan mengenai pemeliharaan alat kesehatan serta cara penyimpanan alat-alat kesehatan dengan baik. Serta perlu adanya standarisasi atau pedoman yang baku dalam memilih alat kesehatan yang dibutuhkan sesuai dengan standart klasifikasi rumah sakit.

2. Bagi Institusi Pendidikan

Sebagai bahan referensi bagi dosen dan mahasiswa dalam menunjang proses belajar mengajar mengenai pemeliharaan alat-alat kesehatan di rumah sakit.

3. Bagi Peneliti Selanjutnya

Penelitian ini memiliki kekurangan dan keterbatasan didalamnya, maka dari itu keterbatasan penelitian ini membuka peluang untuk penelitian selanjutnya untuk menggunakan waktu yang lebih dalam menerapkan metode $5 \mathrm{~S}$ dalam pemeliharaan alat kesehatan di rumah sakit.

\section{DAFTAR PUSTAKA}

Angreany, lisa. (2017). Hubungan Lingkungan Kerja Perawat Dengan Pelaksanaan Dokumentasi Asuhan Keperawatan Di Bangsal Dewasa RSUD Panembahan Senopati. Bantul.

Antoni,J, Brady, M., \& Laureani, A. (2012). Applications of Lean Six Sigma in an Irish hospital. Journal Leadership in Health Services. Vol. 26 No. 4.

Barraza, S., \& F., Manuel. (2012). An exploratory study of $5 \mathrm{~S}$, a multiple case study of multinational organization in Mexico. Asian Journal on Quality. Vol.13 No.1.
Candra,Suwondo. (2012). Penerapan Budaya kerja Unggulan $5 S$ di Indonesia.

Fraenkel, R. J. \& Wallen, E. N. (2009). How to design and evaluate research in education. $7^{\text {th }}$. New York: Mc Graw Hill.

Jimba, M, et al. (2015). Implementation of $5 \mathrm{~S}$ management method for lean healthcare at a health center in Senegal, a qualitative study of staff perception. Journal Global Health Action.

Kobayashi, K. Fisher, R., \& Gapp, R. (2008). Implementing 5S within a japanese context, an integrated management system. Journal Management Decision. Vol. 46 No.4.

Massie, S. (2010). Tesis: Proses Perencanaan Pengadaan Barang Kebutuhan Alat Kesehatan. Tidak dipublikasikan. Jakarta: FKM UI.

Monden, Y. (2000). Sistem Produksi Toyota. Jakarta: PPM.

Notoatmojo, Soekidjo. (2012). Metodologi Penelitian Kesehatan. Jakarta: Rineka Cipta.

Nursalam. (2014). Majanemen Keperawata, Aplikasi Dalam Praktik Keperawatan Profesional. Jakarta: Salemba Medika.

Osaka. T. (2002). Sikap kerja 5S. Jakarta: PPM.

Peraturan Menteri Pertahanan Republik Indonesia. (2016). Tentang Pemeliharaan Alat Kesehatan Rumah Sakit. Jakarta.

Rick, H. (1999). Case study on the 5S program, The five pillars of the visual workplace. Journal Materiel Management Quarterl, Vol. 4 No. 20 Tahun 1999.

Suwondo, C. (2012). Penerapan Budaya Kerja Unggulan 5S (Seri, Seiton, Seiso,Seiketsu dan Shitsuke). Jurnal Menejemen di Indonesia. Jakarta.

Zulparida. (2011). Tesis: Gambaran pelaksanaan pelatihan $5 S$ di Rumah Sakit Depok. Jakarta: FKM UI. 